\title{
PENSÃO POR MORTE: CONCORRÊNCIA ENTRE VIÚVA E EX-ESPOSA ALIMENTADA
}

\section{DEATH BENEFIT: CONCURRENCE BETWEEN THE WIDOW AND THE EX-WIFE RECEIVING FOOD PENSION}

\author{
Fernanda Antunes da Silvai \\ Carla Monnerat Mendonçaii
}

\begin{abstract}
Resumo: $O$ presente artigo objetiva analisar criticamente a legislação previdenciária referente ao benefício da pensão por morte, especificamente em relação à hipótese de concorrência do cônjuge supérstite e o ex-cônjuge recebedor de pensão alimentícia. Além disso, visa verificar as duas posições jurisprudenciais dominantes no assunto, quais sejam, a que privilegia a interação entre o direito previdenciário e o direito civil, sustentando a manutenção dos valores devidos a título de alimentos na pensão por morte, e a que sustenta a primazia da legislação previdenciária ora vigente, com a igualdade de condições entre os beneficiários. Por fim, este trabalho defende a prevalência da primeira corrente, mediante revisão e alteração legislativa, adequando-se a norma previdenciária aos postulados de justiça e equidade.
\end{abstract}

Palavras-Chave: Direito previdenciário. Pensão por morte. Concorrência.

Abstract: This article aims to analyze critically the social security legislation regarding the death benefit, specifically in relation to the hypothesis of competition of the surviving spouse and the former spouse

\footnotetext{
i Graduada em Direito pela Universidade Salgado de Oliveira.

ii Possui graduação em Direito pela Universidade Cândido Mendes, Pós Graduação em Direito do Trabalho e Processo do Trabalho, pela Universidade Cândido Mendes, Mestre em Psicologia pela Universidade Salgado de Oliveira, foi Diretora - IATE CLUBE BRASILEIRO, Diretora do departamento jurídico da EMPRESA MUNICIPAL DE MORADIA URBANIZAÇÃO E SANEAMENTO. Atualmente é advogada do escritório MAM Silva Advogados Associados, professora da Pós Graduação do CBEPJUR - Centro Brasileiro de Estudo e Pesquisa Jurídica, Professora e tutora da Universidade Salgado de Oliveira, Coordenadora da área de Humanas e professora da Univeritas, membro do Conselho dos Notáveis do Instituto Oscar Niemeyer - ISON.
} 
receiving alimony. In addition, it aims to analyze the two dominant juris prudential positions in the subject, the first which favors the interaction between social security law and civil law, supporting the maintenance of the amounts due as food in the death pension, and the second which sustains the prevailing social security legislation, with equal conditions among the beneficiaries. Finally, this paper defends the prevalence of the first position, through revision and legislative amendment, adjusting the social security norm to the postulates of justice and equity.

Keywords: Social security right. Pension for death. Competition. 


\section{INTRODUÇÃO}

A contingência "morte" acarreta necessidade social do tipo ausência de ganhos, deixando o familiar do segurado falecido sem o mínimo indispensável ao seu sustento. Com efeito, são as situações que geram real necessidade social para o indivíduo que se situam no âmbito de proteção do direito previdenciário.

Prestações previdenciárias abarcam os benefícios e serviços devidos aos beneficiários do Regime Geral da Previdência Social (RGPS), uma vez atendidas as hipóteses legais para a sua concessão.

A controvérsia a ser analisada encontra-se embasada pelo art. 77, caput, da Lei da Previdência Social (Lei n 8.213/91), o qual dispõe que, havendo mais de um pensionista, a pensão por morte será rateada entre todos em partes iguais.

Desta maneira, cumpre analisar qual a posição mais acertada, no que tange à determinação das cotas-partes cabíveis, na hipótese de existirem duas pessoas beneficiárias da pensão por morte: o cônjuge atual e o ex-cônjuge que recebia a prestação alimentícia do falecido.

As discussões mais recentes se concentram no percentual devido às beneficiárias, isto é, se este deve ser partilhado $50 \%$ para cada uma das pensionistas ou se deve respeitar o valor fixado a título de alimentos para a ex-esposa alimentada.

Sabe-se que a proteção decorrente da Previdência Social não está restrita apenas aos vínculos de família, e sim de dependência econômica, pois, mesmo não se verificando mais o vínculo familiar, ao persistir a dependência econômica para fins de subsistência, é garantido o direito à percepção de benefício previdenciário, como bem preconiza a Constituição Federal de 1988, em seu artigo 201, inciso V, que prevê o direito à pensão por morte em favor do cônjuge, companheiro ou dependente.

Pensão por morte "é benefício direcionado aos dependentes do segurado, visando à manutenção da família, no caso da morte do responsável pelo seu sustento." (IBRAHIM, 2006, p.521).

Portanto, trata-se de uma prestação assistencial proporcionada pela Previdência Social, com vistas a manter a subsistência das pessoas necessitadas, as quais dependiam do segurado, tendo como finalidade possibilitar que o dependente supérstite promova sua própria existência, visto que contava com um mantenedor e, após o falecimento deste, viu-se em situação de excepcionalidade. 
Para concessão de pensão por morte exige-se, para cônjuge ou companheira, a carência 'casamenteira' de 2 (dois) anos de união, bem como 18 (dezoito) meses de contribuições, porém, em se tratando de filhos menores de 21 anos, não há esta exigência, bastando apenas que o óbito tenha ocorrido durante o período em que o trabalhador tinha qualidade de segurado.

\section{O VÍNCULO PREVIDENCIÁRIO E A OBRIGAÇÃO DE PRESTAR ALIMENTOS}

Entre as classes de dependentes previstas na lei previdenciária (Lei $n^{\circ} 8.213 / 91$ ), no art. 16, encontra-se o cônjuge (inciso l) e, no artigo 76, §2, a figura do cônjuge divorciado ou separado judicialmente que recebe pensão alimentícia, este concorrendo em igualdade de condições com aquele.

Partindo-se da premissa que a paz social é fruto da aplicação da lei e que a Previdência Social está nitidamente ligada ao fim social, assentada no Princípio Constitucional da Dignidade da Pessoa Humana, o sistema protetivo da previdência visa ao fornecimento de meios mínimos para a continuidade existencial digna do beneficiário.

Ressalta-se que, no que diz respeito ao tema, é notório que em nada se assemelham a obrigação civil de prestar alimentos, a qual se extingue com a morte, com o vínculo previdenciário que surge após a morte do segurado, a qual vincula a ex-esposa alimentada à Administração.

Todavia, cabe elucidar algumas definições para uma análise contextualizada sobre a questão, pois, apesar da não semelhança entre a obrigação de prestar alimentos e o vínculo previdenciário da pensão por morte, não se pode negar que, em sendo a condição de alimentada e de dependência econômica fatores que a incluem como beneficiária ao direito à percepção do benefício pensão por morte, importante se faz a abordagem da natureza dos alimentos.

Alimentos são prestações para satisfazer as necessidades vitais de quem não pode provê-las por si.

A doutrina divide o conceito de alimentos em duas classificações, de acordo com sua abrangência. Portanto, podem ser classificados como civis e naturais, o primeiro, visa a assegurar o padrão de vida do alimentado, o segundo, a sobrevivência. "Os alimentos, assim, traduzem-se em prestações periódicas fornecidas a alguém para suprir essas necessidades e assegurar sua subsistência." (VENOSA, 2012, p.362). 
Frisa-se que estes devem ser fixados na proporção das necessidades do reclamante e dos recursos da pessoa obrigada, conforme redação do art. 1.694, $\S 1^{\circ}$ do Código Civil de 2002, in verbis: "Os alimentos devem ser fixados na proporção das necessidades do reclamante e dos recursos da pessoa obrigada".

Importante destacar que há distinção, no ordenamento, quanto aos alimentos devidos aos parentes e aos cônjuges ou companheiros.

Sobre o assunto, elucida Sílvio de Salvo Venosa (2012, p. 363):

É importante ressaltar uma distinção que tem reflexos práticos: o ordenamento reconhece que o parentesco, o jus sanguinis, estabelece o dever de alimentar, assim como aquele decorrente do âmbito conjugal definido pelo dever de assistência e socorro mútuo entre cônjuges e, modernamente, entre companheiros.

Portanto, tem que ser feita uma análise do teor do art. $76, \S 2^{\circ}$ e o art. 77, caput da Lei da Previdência (Lei $n^{\circ}$ 8.213/91), uma vez que os referidos dispositivos colocam os beneficiários no mesmo patamar de igualdade para o recebimento da pensão por morte. Afinal, a proteção previdenciária que a Carta Magna preconiza é de proteção da família.

Desta feita, igualar a ex-esposa alimentada, no qual o vínculo familiar já se extinguiu, com a figura do cônjuge e, ainda, com a dos filhos, para uma concorrência igualitária com relação à percepção da pensão por morte, traduz-se na proteção a qual a Constituição Federal concedeu à família em seu artigo 226, caput?

\section{CORRENTES JURISPRUDENCIAIS}

Antes de adentrar neste tópico, mister salientar, quanto ao precedente, afirma Luiz Guilherme Marinoni, que este não é sinônimo de decisão judicial. Para o autor, fundado na melhor doutrina internacional, só há sentido falar em precedentes quando se observa que uma decisão é dotada de determinadas características, "basicamente a potencialidade de se firmar como paradigma para a orientação dos jurisdicionados e magistrados." (MARINONI, 2010, p. 215). Ou seja, sem esta pretensão de universalidade, tem-se uma simples decisão judicial. Mas apenas isso não basta: para se ter um verdadeiro precedente "é preciso que a decisão enfrente todos os principais argumentos relacionados à questão de direito posta na moldura do caso concreto". (MARINONI, 2010, p. 216). 
Convém mencionar que o precedente pode se formar a partir de um conjunto de decisões, a que se dá o nome de jurisprudência. É de se notar, porém, que a jurisprudência pode ou não formar um precedente, pois, para Marinoni, esta definição depende dos requisitos da pretensão de universalidade e da completude do julgado, ao analisar os argumentos pertinentes. Em síntese, "é possível dizer que o precedente é a primeira decisão que elabora a tese jurídica ou é a decisão que definitivamente a delineia, deixando-a cristalina". (MARINONI, 2010, p. 217).

A matéria ainda não está pacificada, posto que de nossos Tribunais emergem decisões antagônicas e que a doutrina ainda não se posicionou sobre o tema.

\subsection{Primeira corrente jurisprudencial}

Os partidários desta corrente sustentam que a norma prevista no art. 77, caput, da Lei $n^{\circ} 8.213 / 91$, deveria ser interpretada à luz da coisa julgada e do ato jurídico perfeito, de modo que a divisão fosse aplicada por força do princípio da gravitação jurídica, seguindo a pensão por morte (acessória) a sorte da pensão alimentícia (principal).

Asseveram que:

não se pode trazer, apenas por força de interpretação literal da lei, a conclusão de que, com a morte do segurado, toda a situação de fato se alterou de um dia para o outro, com vistas a igualar o percentual de recebimento de pensão, sob pena de se retirar de quem necessita do percentual maior, para atribuir mais a quem antes não necessitava de tanto. (BRASIL, 2005, p. 5-6).

Há também decisões no sentido de que, como o benefício é oriundo da relação conjugal, há que ser mantido o valor fixado em sede de obrigação alimentar. Vejamos:

Afirmam ainda que, de acordo com o art. 884, do Código Civil Brasileiro, a saber: "Art. 884. Aquele que, sem justa causa, se enriquecer à custa de outrem, será obrigado a restituir o indevidamente auferido, feita a atualização dos valores monetários." Trata-se da definição de enriquecimento sem causa. Portanto, deve ser problematizado o fato de que subitamente haverá uma alteração radical no quantum da pensão alimentícia justamente no momento de fragilidade de um parente próximo. 
Enquanto uma parte verá seus proventos reduzidos, a outra perceberá considerável aumento injustificado, configurando, assim, o enriquecimento sem causa.

Convém transcrever, a título de ilustração dessa primeira corrente, o julgado abaixo:

PROCESSUAL CIVIL. PREVIDENCIÁRIO. PENSÃO POR MORTE. CONCORRÊNCIA ENTRE ESPOSA E EX-ESPOSA. RATEIO DA PENSÃO EM OBEDIÊNCIA AO FIXADO NO ACORDO DE ALIMENTOS. BINÔMIO NECESSIDADE/ POSSIBILIDADE. ARTIGOS 76, § 20, E 77, DA LEI $N^{\circ}$ 8.213/91. VALOR DA PENSÃO ALIMENTÍCIA. VINCULAÇÃO AO VALOR DA PENSÃO POR MORTE. APELAÇÃO DA PARTE AUTORA PARCIALMENTE PROVIDA. SENTENÇA REFORMADA. CONCESSÃO DA TUTELA ESPECÍFICA.

1 - A pensão por morte é regida pela legislação vigente à época do óbito do segurado, por força do princípio tempus regit actum, encontrando-se regulamentada nos arts. 74 a 79 da Lei $n^{\circ} 8.213 / 91$. Trata-se de benefício previdenciário devido aos dependentes do segurado falecido, aposentado ou não. 2 - O benefício independe de carência, sendo percuciente para sua concessão: a) a ocorrência do evento morte; b) a comprovação da condição de dependente do postulante; e c) a manutenção da qualidade de segurado quando do óbito, salvo na hipótese de o de cujus ter preenchido em vida os requisitos necessários ao deferimento de qualquer uma das aposentadorias previstas no Regime Geral de Previdência Social - RGPS.

3 - A celeuma diz respeito à redução do valor da pensão por morte paga à corré Maria Almeida, posto que, ao entendimento da autora, o valor correto é no percentual de $50 \%$ do salário mínimo, por força de determinação judicial, ocorrida nos autos da ação de divórcio entre o de cujus e a primeira esposa.

4 - O evento morte restou comprovado com a certidão de óbito de fl.17, na qual consta o falecimento do Sr. Ornélio Benedito de França em 10/11/2004.

5 - O requisito relativo à qualidade de segurado do de cujus restou incontroverso, considerando a pensão já paga à autora NB 135.913.005-2, (fl. 22), e o requisito relativo à dependência econômica da corré é questão incontroversa, posto que recebia pensão alimentícia do ex-cônjuge.

6 - Os artigos 76 , § $2^{\circ}$ e o 77 caput da Lei $n^{\circ} 8.213 / 91$ estabelecem os critérios de rateio no recebimento 
de pensão por morte a mais de um dependente e especificamente para o pagamento do benefício ao cônjuge divorciado ou separado judicialmente ou de fato que recebia pensão de alimentos.

7 - In casu, a parte autora, Sra. Sonia Maria de Araújo de França, alegou que é viúva do instituidor da pensão Sr. Ornélio Benedito de França, o qual fora casado em primeiras núpcias com Maria Almeida, em cujo divórcio ficou estabelecido o pagamento de pensão alimentícia no valor de $1 / 2$ (meio) salário mínimo. Contudo, a autarquia previdenciária, ao implantar a pensão por morte, o fez no equivalente a $50 \%$ do valor da renda mensal devida, para cada uma das dependentes, o que ultrapassa a quantia devida à segunda corré, em flagrante desrespeito aos limites da coisa julgada.

8 - O decidido nos autos da ação de divórcio e posteriormente na ação revisional de alimentos, que tramitaram perante a $2^{\mathrm{a}}$ Vara cível da Comarca de São Vicente, em que foram partes o de cujus, e a Sr. Maria Almeida é ato jurídico perfeito e deve obedecer ao binômio necessidade de quem reclama alimentos e a possibilidade econômicofinanceira daquele que pode supri-los.

9 - No caso, a aferição da necessidade econômica que norteou o valor estabelecido na época para a pensão alimentícia, devida pelo ex-cônjuge (agora falecido), teve por base exatamente a medida da necessidade econômica da corré Sra. Maria Almeida, que certamente concordou com os termos do acordo da revisão dos alimentos ocorrido na audiência de conciliação, posto que renunciou eventual interposição de recurso, conforme o termo de audiência, datado de 06/05/2003, anexado à fl. 81.

10 - Com a morte do segurado instituidor da pensão alimentícia a aferição da necessidade econômica se torna dificultada, de modo que a conclusão a respeito da referida necessidade é aquilo que já se estabeleceu sem impugnação em vida.

11 - A jurisprudência tem admitido o rateio da pensão em forma diversa do que consta no artigo 77 da Lei no $8.213 / 91$, quando o falecido possuía duas dependentes em vida e uma tinha direito à pensão alimentícia, com percentual fixado em decisão judicial, que deve ser mantido para efeito de rateio de pensão alimentícia.

12 - Diante do ato jurídico perfeito e em respeito à coisa julgada não há como modificar o estabelecido na ação revisional de alimentos mencionada e consi- 
derar que a corré Maria Aparecida dispusesse de dependência econômica com relação ao segurado em patamar maior que os $2 / 3$ (dois terços) do salário mínimo acordado anteriormente.

13 - A pensão por morte deve ser rateada entre a viúva e a ex-mulher divorciada, nos moldes anteriormente acordado, ou seja $2 / 3$ (dois terços) do salário mínimo vigente, em respeito ao determinado na ação de revisional de alimentos transitada em julgado.

14 - O termo inicial do benefício deve ser a data da citação, em 14/10/2005, (fl. 27-verso), momento em que a autarquia previdenciária tomou ciência da pretensão da parte autora.

15 - Os juros de mora devem ser fixados de acordo com o Manual de Orientação de Procedimentos para os Cálculos na Justiça Federal, por refletir as determinações legais e a jurisprudência dominante.

16 - A correção monetária dos valores em atraso deverá ser calculada de acordo com o Manual de Orientação de Procedimentos para os Cálculos na Justiça Federal, naquilo em que não conflitar com o disposto na Lei no 11.960/09, aplicável às condenações impostas à Fazenda Pública a partir de 29 de junho de 2009.

17 - Em se tratando de beneficiários da assistência judiciária gratuita, não há custas, nem despesas processuais a serem reembolsadas.

18 - Os honorários advocatícios são devidos inteiramente à autora no percentual de $10 \%$ (dez por cento) sobre o valor das parcelas devidas até a sentença (Súmula 111, STJ), e deverão ser pagos pelos corréus, em rateio de $5 \%$ (cinco por cento) para cada um.

19 - A hipótese da ação comporta a outorga de tutela específica nos moldes do art. 497 do Código de Processo Civil. Dessa forma, em atenção a expresso requerimento da parte autora, visando assegurar o resultado concreto buscado na demanda e a eficiência da prestação jurisdicional, independentemente do trânsito em julgado, deve ser seja enviado e-mail ao INSS - Instituto Nacional do Seguro Social, instruído com os documentos da parte autora e da corré, a fim de serem adotadas as providências cabíveis ao cumprimento desta decisão, para a modificação do percentual do benefício nos moldes fixados no prazo máximo de 20 (vinte) dias.

21 - Apelação da parte autora provida em parte. (BRASIL, 2017, grifo nosso). 


\subsubsection{Segunda corrente jurisprudencial}

Já os adeptos desta outra corrente afirmam que, independentemente do que fora estipulado em razão da separação ou em ação de alimentos, há que ser respeitada a lei previdenciária, pois, no pós-morte do beneficiário não impera o vínculo familiar civil, e sim, o vínculo assistencial derivado da Previdência Social.

Desta maneira, considera-se totalmente infundadas as alegações em sentido contrário, visto que, asseveram que a lei previdenciária é clara ao tratar do assunto, dispensando qualquer tipo de interpretação da lei diversa da interpretação literal ou gramatical. A fim de ilustrar a segunda corrente, segue transcrição da ementa de julgado do Superior Tribunal de Justiça:

ADMINISTRATIVO. AGRAVO REGIMENTAL NO RECURSO ESPECIAL. SERVIDOR PÚBLICO. PENSÃO POR MORTE. BENEFÍCIO CUJO VALOR DEVE SER RATEADO, IGUALMENTE, ENTRE A VIÚVA E A EX-ESPOSA QUE RECEBIA PENSÃO ALIMENTÍCIA. LEI No 8.112/1990. AUSÊNCIA DE VIOLAÇÃO À COISA JULGADA FORMADA NA AÇÃO DE DIVÓRÇO. AGRAVO IMPROVIDO.

1. Nos termos do art. 217 c.c. o art. 218, § 1. da Lei n. ${ }^{\circ} 8.112 / 90$, o rateio da pensão vitalícia entre as beneficiárias habilitadas deve ser feito em cotas-partes iguais. Precedentes.

2. Não se pode falar em desrespeito à coisa julgada decorrente da ação de divórcio, que fixou o valor da pensão alimentícia em favor da ex-esposa, porquanto com a morte do servidor público federal cessou aquela relação jurídica e surgiu uma nova, de natureza previdenciária, regulada por legislação específica.

3. A decisão judicial transitada em julgado possui limites objetivos e subjetivos, desta forma seus efeitos ficam delimitados pelo pedido e pela causa de pedir apresentados na petição inicial do processo de conhecimento, não podendo beneficiar ou prejudicar terceiros que não integraram a relação jurídica.

4. Agravo regimental improvido. (BRASIL, 2015).

Aduzem, ainda, que não há que se perquirir os institutos da coisa julgada e da segurança jurídica, uma vez que, com a morte do segurado extingue-se o vínculo alimentar e nasce o vínculo previdenciário que é 
totalmente desvinculado do que outrora existia. Mais ainda, defendem a igualdade de direitos entre ambas as beneficiárias posto que se situam na mesma classe.

\section{CONSIDERAÇÕES FINAIS}

No Direito Previdenciário, há que ser levado em consideração, na interpretação da legislação pertinente, o seu objetivo, qual seja, a proteção da sociedade aos seus membros, capaz de atender aos anseios e necessidades sociais, e meio para atingir a justiça, como fim da ordem social.

A interpretação da norma previdenciária objetiva extrair o verdadeiro significado do regramento jurídico. O intérprete deve penetrar na norma, buscando seu sentido, seu alcance e a extensão de sua finalidade. Qualquer lei necessita de interpretação. Mesmo uma lei "clara" deve ser interpretada, pois, para se chegar à conclusão de que esta tem sentido auto explicável, é necessário, de antemão, interpretá-la.

Com efeito, a interpretação é a construção de um sentido, a norma é construída em um procedimento em que o texto é apenas um limite, mas que não encerra o alcance e os contornos da norma a ser aplicada. Nesse processo, o intérprete se utiliza do texto como um ponto de partida, uma baliza inicial e, posteriormente, são acrescentados elementos diversos, como dados do caso concreto, a realidade social, cultura, valores e visões de mundo do intérprete, dentre outros. A norma é construída pelo intérprete no momento de sua aplicação, conforme demonstra Eros Grau:

O fato é que a norma é construída pelo intérprete, no decorrer do processo de concretização do direito. O texto, preceito jurídico, é, como diz Friedric Müller, matéria que precisa ser "trabalhada".

Partindo do texto da norma (e dos fatos), alcançamos a norma jurídica, para então caminharmos até a norma de decisão, aquela que confere solução ao caso. Somente então se dá a concretização do direito. Concretizá-lo é produzir normas jurídicas gerais nos quadros de solução de casos determinados [Müller].

A concretização implica um caminhar do texto da norma para a norma concreta (a norma jurídica), que não é ainda, todavia, o destino a ser alcançado; a concretização somente se realiza em sua plenitude no passo seguinte, quando é definida a norma de decisão, apta a dar solução ao conflito que consubstancia o caso concreto. 
Por isso sustento que interpretação e concretização se superpõem. Inexiste, hoje, interpretação do direito sem concretização; esta é a derradeira etapa daquela. (GRAU, 2006, p. 28).

Portanto, a interpretação faz-se imperiosa para que se alcance a intenção da lei, com a busca do fim desejado pela lei, não sendo suficiente apenas a leitura da letra da norma.

Para tal, há de se fazer uma análise em todo o ordenamento jurídico, buscando-se textos de outros ramos do Direito para que se possa detectar qual é o sentido da norma previdenciária.

Com este intuito, necessário se faz reconhecer que, apesar da afirmação de que o Direito Previdenciário se afasta do Direito de Família, ambos possuem um objeto em comum: as relações em família. Com efeito, a pensão por morte é o benefício que mais suscita a íntima relação do Direito Previdenciário com o Direito Civil, obrigando o estudioso a conhecer notáveis institutos técnicos civilistas para que o legislador pátrio empreenda um profundo estudo sobre a realidade social, as mudanças dos costumes e que aprecie a necessidade de inteira revisão do benefício.

O que se percebe, através do estudo da legislação previdenciária, é seu caráter assistencial e protetivo, presente em todo o ordenamento jurídico que rege a matéria. Portanto, é nítido o intuito de preservação do direito à subsistência e condição de vida do dependente beneficiário.

Frisa-se que, apesar da dicotomia existente entre as duas correntes jurisprudenciais que tratam sobre o rateio entre viúva e ex-esposa alimentada, a doutrina é taxativa ao reconhecer que a lei é clara e, portanto, o rateio deve se dar conforme o previsto na Lei Previdenciária. Mas a decisão precisa ser contundente ao acolher e rejeitar argumentos, bem como se mostrar adequada para a orientação dos demais juízes e cidadãos.

Por isso, a sociedade clama por uma análise mais atenta da lei, a fim de proporcionar aos jurisdicionados a manutenção da harmonia e da paz social, indispensáveis à vida em sociedade, evitando, assim, o resultado segundo o qual um dos beneficiários possa ser "premiado" pela morte do segurado, recebendo um aumento no valor da pensão, enquanto outro deverá suportar a dor de perder o companheiro e grande parte da renda familiar.

Ressalta-se que a ideia de supressão e substituição da renda mantenedora do beneficiário deveria evitar o enriquecimento sem causa pela 
credora de alimentos na hipótese em que, por exemplo, mesmo só percebendo $10 \%$ da renda mensal auferida pelo segurado em vida, viria a perceber, com o óbito deste, $50 \%$ de seu salário-de-benefício, aumentando seu ganho mensal sem que tenha dado causa a tanto. Além disso, há que se considerar que o segurado deixou outra dependente preferencial, caracterizando, assim, a injustiça na repartição igualitária entre ela e aquela credora de alimentos, pois retira da dependente supérstite uma considerável parcela dos ganhos por eles compartilhados enquanto era vivo o instituidor.

É interessante, porém, registrar que a legislação anterior à Lei $n^{\circ}$ $8.213 / 91$ previa exatamente o que ora se propõe para alteração legislativa no presente artigo. O texto abaixo transcrito, constante do Decreto $n^{\circ}$ 89.312/84 (que trazia a anterior Consolidação das Leis da Previdência Social), assim estabelecia:

Art. 49. A concessão da pensão não é adiada pela falta de habilitação de outro possível dependente, e qualquer inscrição ou habilitação posterior que importe em exclusão ou inclusão de dependente só produz efeito a contar da data em que é feita.

$\S 2^{\circ} \mathrm{O}$ cônjuge que, embora desquitado, separado judicialmente ou divorciado, está recebendo alimentos, tem direito ao valor da pensão alimentícia judicialmente arbitrada, destinando-se o restante à companheira ou ao dependente designado. (BRASIL, 1984, grifo nosso).

A legislação, portanto, tão somente garantia ao ex-cônjuge pensionista (credor de alimentos) o direito à manutenção da percepção do percentual percebido a título de pensão alimentícia judicialmente arbitrada, destinando-se o restante à companheira ou ao dependente designado. Conseguia-se, então, conciliar a imposição judicial (pensão alimentícia) com o sentido econômico da relação de dependência.

Eis, portanto, o ponto que haveria de ser objeto de imediata revisão e alteração legislativa, adequando-se a norma previdenciária aos postulados de justiça e equidade que sempre devem nortear o trabalho do legislador, num primeiro plano, e, num segundo, do aplicador do direito.

Destaca-se, ainda, que a manutenção da divisão dos valores da pensão nos moldes fixados ainda em vida não importa qualquer prejuízo 
para os cofres públicos. Trata-se, simplesmente, de uma revisão da interpretação da legislação, beneficiando a parte que mais necessita com um valor proporcionalmente maior.

Cabe ressaltar que no direito brasileiro, à luz do princípio da justiça distributiva, o princípio da isonomia deve ser lido com vistas ao alcance de uma igualdade material que leve em conta a situação fática, e não uma mera igualdade na forma.

"A interpretação da norma extrai dela distinções, discrimens, desequiparações que não foram professadamente assumidos por ela de modo claro, ainda que por via implícita." (MELLO, 1999, p. 25)

Assim sendo, tem-se que investigar, de um lado, aquilo que é adotado como critério discriminatório; de outro lado, se há justificativa racional para, à vista do traço desigualador, atribuir o específico tratamento jurídico construído em função da desigualdade proclamada.

\section{REFERÊNCIAS}

BRASIL. Constituição (1988). Disponível em:

<http://www.planalto.gov.br/ccivil_03/constituicao/constituicao.htm>. Acesso em: 27 ago. 2017.

BRASIL. Decreton`89.312, de23 dejaneirode 1984.Disponívelem:<http:// sislex.previdencia.gov.br/paginas/23/1984/89312.htm>. Acesso em: 27 ago. 2017.

BRASIL. Lei n 8.213, de 24 de julho de 1991. Dispõe sobre os Planos de Benefícios da Previdência Social e dá outras providências. Disponível em: <http://www.planalto.gov.br/Ccivil_03/leis/L8213cons.htm>. Acesso em: 07 jul. 2017.

BRASIL. Lei n 10.406, de 10 de janeiro de 2002. Institui o Código Civil. Disponível em: <http://www.planalto.gov.br/ccivil_03/leis/2002/L10406. htm>. Acesso em: 15 set. 2017.

BRASIL. Superior Tribunal de Justiça. Agravo regimental no recurso especial no 993.646-RJ (2007/0229109-1). Agravante: Maria Alice de Barros Rocco. Agravado: Myrna Katona Faria. Relator: Ministro Walter de Almeida Guilherme. Brasília, DF, 4 de dezembro de 2014. Revista Eletrônica da Jurisprudência do STJ, Brasília, DF, 2015. 
Disponível em: <https://ww2.stj.jus.br/processo/revista/documento/ mediado/?componente $=$ ATC\&sequencial $=39861127 \&$ num_registro $=$ $200702291091 \&$ data $=20150203 \&$ tipo $=5 \&$ formato $=H T M L>$. Acesso em: 16 mar. 2018.

BRASIL. Tribunal Regional Federal (2. Região). Apelação cível $\mathbf{n}^{\circ}$ 2002.51.01.503923-2. Apelante: Celia Diehl Corazza. Apelada: Marina de Souza Pires. Relator: Desembargador Federal Abel Gomes. Rio de Janeiro, 20 de julho de 2005. Disponível em: <http://www10.trf2.jus.br/ consultas/?movimento $=$ cache $\& q=$ cache: $1 \mathrm{XgHbw8mK5YJ}$ :trf2nas.trf.net/ iteor/TXT/RJ0108110/1/3/119781.rtf +200251015039232\&site=v2_jurisprudencia\&client $=\mathrm{v} 2$ _index\&proxystylesheet $=\mathrm{v} 2$ index $\& \mid \mathrm{r}=\mathrm{lang}$ pt\&ie $=U T F-8 \&$ output $=x m l \_n o \_d t d \& a c c e s s=p \& o e=U T F-8>$. Acesso em: 16 mar. 2018. Data de disponibilização no extinto Diário de Justiça da União (DJU): 09 ago. 2005.

BRASIL. Tribunal Regional Federal (3. Região). Apelação cível nº 0008644 55.2005.4.03.6104/SP (2005.61.04.008644-5/SP). Apelante: Sonia Maria de Araujo Franca. Apelada: Instituto Nacional do Seguro Social - INSS. Relator: Desembargador Federal Carlos Delgado. São Paulo, 04 de setembro de 2017. Diário Eletrônico da Justiça Federal da $3^{\mathbf{a}}$ Região, São Paulo, n. 173, 18 set. 2017. Judicial I. Disponível em: <http://web.trf3.jus.br/diario/Consulta/VisualizarDocumento?CodigoTipoPublicacao $=2 \&$ CodigoOrgao $=1 \&$ CodigoDocumento $=6219797 \&$ Id Materia $=109253 \&$ NumeroPro cesso $=200561040086445>$. Acesso em: 15 mar. 2018 .

GRAU, Eros Roberto. Ensaio e discurso sobre a interpretação/aplicação do Direito. 4.ed. São Paulo: Malheiros, 2006.

IBRAHIM, Fábio Zambitte. Curso de Direto Previdenciário. 7.ed. Rio de Janeiro: Impetus, 2006.

MARINONI, Luiz Guilherme. Precedentes Obrigatórios. São Paulo: Revista dos Tribunais, 2010.

MELLO, Celso Antônio Bandeira de. Conteúdo Jurídico do Princípio da Igualdade. 3.ed. e atual. São Paulo: Malheiros Editores, 1999.

VENOSA, Sílvio de Salvo. Direito Civil-Direito de Família. 12.ed. São Paulo: Atlas, 2012. 